Terbit online pada laman web jurnal : http://jurnal.iaii.or.id

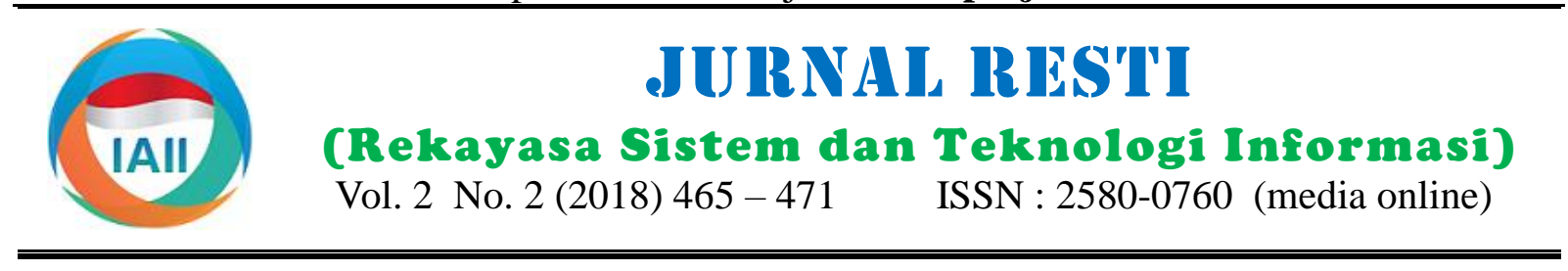

\title{
ISO 9126 Untuk Pengujian Kualitas Aplikasi Perpustakaan Senayan Library Management System (SLiMS)
}

Petrus Dwi Ananto Pamungkas

Jurusan Teknik Informatika; STMIK Bina Insani; petrusdwi@binainsani.ac.id

\begin{abstract}
The rapid development of information systems has made changes almost in all areas of human activity, including the management of college libraries. The presence of reliable software (application) library Senayan Library Management System (SLiMS), it is very helpful to the person in charge of college library in managing the library, e.g: inputing the data, searching, borrowing and returning the library collection. The large number of usage of SLiMS application is expected not only because of its Open Source Software or free usage and license but also because of its good application quality. Using the Functionality, Reliability, Usability, Efficiency, Maintainability and Portability aspects of ISO 9126 standards, it is possible to test the quality of SLiMS application. The data collection method used is Google Forms in creating and distributing questionnaire and interview to some of the person in charge of college library. The result of data collection is processed to obtain information that SLiMS application classified as VERY GOOD category. It means that SLiMS application which has been used by some of the person in charge of college library, obviously it has excellent quality and very helpful in the management of college libraries.
\end{abstract}

Keywords: ISO 9126, library, Senayan Library Management System (SLiMS), application quality testing.

\begin{abstract}
Abstrak
Perkembangan sistem informasi yang cepat telah membuat perubahan hampir di semua bidang kegiatan manusia, termasuk pengelolaan perpustakaan di perguruan tinggi. Kehadiran perangkat lunak (aplikasi) perpustakaan Senayan Library Management System (SLiMS) yang handal ternyata sangat membantu para penanggung jawab perpustakaan di perguruan tinggi dalam mengelola perpustakaan, mulai dari input data, pencarian sampai dengan transaksi peminjaman dan pengembalian koleksi pustaka. Banyaknya penggunaan aplikasi SLiMS diharapkan bukan saja karena sifatnya yang Open Source Software atau bebas penggunaan dan lisensi melainkan juga dikarenakan kualitas aplikasi yang baik. Dengan menggunakan aspek Functionality (Fungsionalitas), Reliability (Kehandalan), Usability (Kebergunaan), Efficiency (Efisiensi), Maintainability (Pemeliharaan), dan Portability (Portabilitas) yang ada dalam standar ISO 9126 dimungkinkan untuk dilakukan pengujian kualitas aplikasi SLiMS. Adapun metode pengumpulan data yang digunakan adalah penggunaan Google Forms dalam membuat dan menyebarkan kuesioner serta wawancara kepada beberapa penanggung jawab perpustakaan perguruan tinggi. Hasil pengumpulan data tersebut untuk kemudian diolah hingga menghasilkan informasi bahwa aplikasi SLiMS termasuk dalam kategori SANGAT BAIK. Hal ini berarti bahwa aplikasi SLiMS yang selama ini telah digunakan oleh beberapa penanggung jawab perpustakaan perguruan tinggi ternyata memiliki kualitas sangat baik dan sangat membantu dalam pengelolaan perpustakaan yang ada di perguruan tinggi.
\end{abstract}

Kata kunci : ISO 9126, perpustakaan, Senayan Library Management System (SLiMS), pengujian kualitas aplikasi.

\section{Pendahuluan}

Saat ini, pengelolaan informasi yang cepat dan akurat menjadi hal yang sangat dibutuhkan karena ketersediaan informasi yang banyak dan distribusinya yang cepat dari sumber informasi sampai pengguna informasi. Demikian halnya dengan pengelolaan informasi di perpustakaan. Perpustakaan sebagai tempat pendidikan, penelitian, dan informasi menjadi salah satu tempat yang membutuhkan pengelolaan informasi yang cepat dan akurat sesuai tujuan perpustakaan yaitu memberikan layanan kepada pemustaka, meningkatkan kegemaran membaca, serta memperluas wawasan dan pengetahuan untuk mencerdaskan kehidupan bangsa [1].

Guna mengelola informasi yang cepat dan akurat tersebut maka perpustakaan, termasuk perpustakaan di perguruan tinggi, maka dikembangkan layanan perpustakaan berbasis teknologi informasi dan 
komunikasi. Namun demikian, penggunaan teknologi informasi dan komunikasi dalam pelaksanaanya harus sesuai dengan arah dan tujuan manajemen perpustakaan yang ada pada perguruan tinggi masingmasing. Alangkah baiknya jika teknologi informasi dan komunikasi yang telah dibuat sesuai dengan manajemen perpustakaan perguruan tinggi tersebut sehingga menjadi lebih optimal penggunaannya.

Kehadiran sistem informasi Senayan Library Management System (SLiMS) yang merupakan hasil karya anak bangsa Indonesia diharapkan menjadi aplikasi pengelola perpustakaan yang dapat diandalkan. Penggunaannya pun dibebaskan dari biaya penggunaan maupun biaya lisensi karena termasuk dalam kategori Open Source Software [2]. Untuk mengetahui kualitas aplikasi SLiMS maka dilakukan pengujian kualitas aplikasi dengan menggunakan standar ISO 9216.

\section{Tinjauan Pustaka}

\subsection{Konsep Dasar ISO 9126}

Pengujian perangkat lunak adalah proses mengeksekusi program secara intensif untuk menemukan kesalahahkesalahan. Pengujian tidak hanya untuk mendapatkan program yang benar, namun juga memastikan bahwa program tersebut bebas dari kesalahan-kesalahan untuk segala kondisi [3]. Pengujian perangkat lunak adalah elemen kritis dari jaminan kualitas perangkat lunak dan mempresentasikan spesifikasi, desain dan pengkodean [4].

ISO 9126 merupakan salah satu framework standar internasional yang digunakan untuk melakukan pengujian kualitas perangkat lunak, yang dibuat oleh International Organization for Standardization (ISO) dan International Electrotechnical Commission (IEC). Standar internasional ini memiliki kemampuan dalam mendefinisikan kualitas produk perangkat lunak, karakteristik mutu, model, dan metrik terkait untuk mengevaluasi dan menetapkan kualitas sebuah produk perangkat lunak. Model ISO 9126 memiliki 6 (enam) faktor dan beberapa subfaktor [5].

Berdasarkan Gambar 1 berikut dapat dijelaskan keenam karakteristik model ISO 9126 antara lain Functionality (Fungsionalitas) adalah kemampuan perangkat lunak dalam menyediakan fungsi sesuai dengan kebutuhan pengguna ketika digunakan dalam kondisi yang spesifik. Sebuah website harus mampu diakses oleh pengguna dengan lingkungan sistem yang berbeda tanpa mengurangi fungsi yang ada; Reliability (Kehandalan) adalah kemampuan perangkat lunak untuk mempertahankan kinerjanya ketika digunakan dalam kondisi tertentu. Kehandalan suatu perangkat lunak dapat ditentukan dari jumlah masukan yang dapat menyebabkan kegagalan pada saat sedang dijalankan. Hal ini dapat diamati oleh pengguna; Usability (Kebergunaan) berkaitan dengan apakah produk dapat mencapai tujuan tertentu secara efektif, efisien, dan memperoleh kepuasan setelah digunakan. Aspek kebergunaan dapat diukur dengan menggunakan instrumen berupa kuisioner. Kuisioner ini akan diisi oleh pengguna setelah mereka mencoba menggunakan aplikasi. Kemudahan penggunaan adalah derajat tentang bagaimana kemudahan perangkat lunak digunakan, dimana hal ini sering diindikasikan menggunakan sub-atribut kemudahan untuk dipahami, kemudahan untuk dipelajari, dan operabilitas; Efficiency (Efisiensi) berkaitan dengan kemampuan perangkat lunak untuk memberikan kinerja yang sesuai terhadap jumlah sumber daya yang digunakan pada saat keadaan tersebut. Apabila ingin menciptakan perangkat lunak yang handal, aspek efficiency harus benar-benar diperhatikan. Penggunaan sumber daya yang tidak efisien, misalnya menggunakan algoritma yang tidak tepat dapat menyebabkan kinerja perangkat lunak menjadi lamban; Maintainability (Pemeliharaan) berkaitan dengan kemampuan perangkat lunak untuk dimodifikasi. Modifikasi meliputi koreksi, perbaikan atau adaptasi terhadap perubahan lingkungan, persyaratan, dan spesifikasi fungsional; dan Portability (Portabilitas) berkaitan dengan kemampuan suatu perangkat lunak beroperasi atau bekerja dalam lingkungan yang berbeda-beda. Untuk menguji tingkat portabilitas dari aplikasi berbasis web, aplikasi tersebut dicoba dijalankan menggunakan browser yang berbeda. Selain itu, percobaan menggunakan perangkat yang berbeda juga dapat menentukan tingkat portabilitas dari software tersebut.

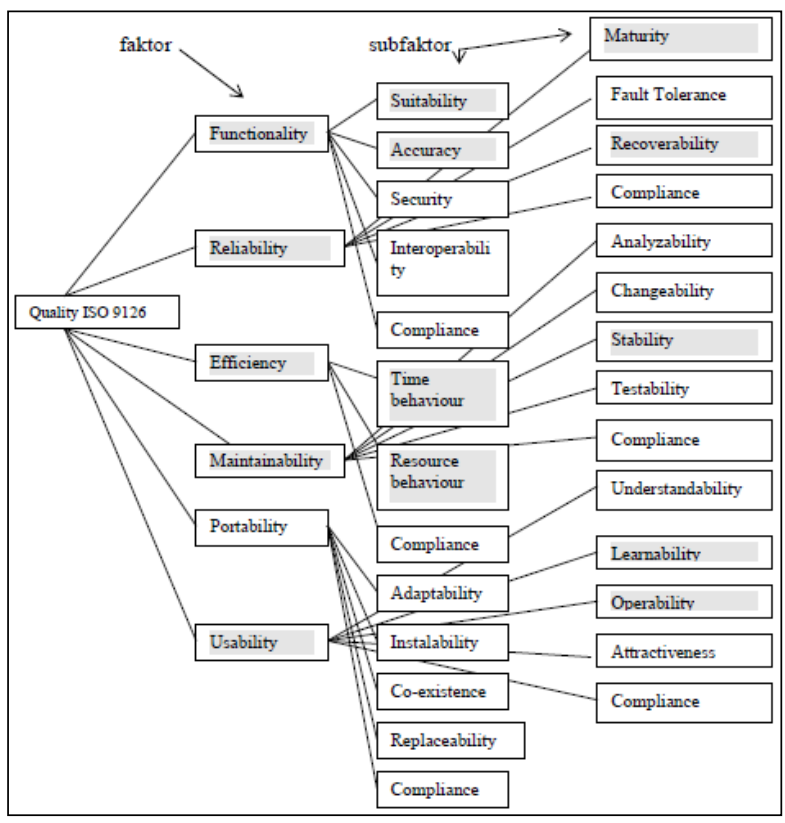

Gambar 1. Faktor dan Subfaktor Kualitas ISO 9126

Pengujian sistem informasi merupakan proses mengumpulkan dan mengevaluasi fakta-fakta untuk menentukan apakah sistem informasi melindungi aset, memiliki integritas data, dan membantu tujuan organisasi dapat tercapai [5]. Kegiatan pengujian sistem informasi perpustakaan SLiMS pada beberapa 
perguruan tinggi mengacu pada standar ISO 9126. Standar ISO 9126 digunakan karena mempunyai kompromi yang cukup baik dalam keluasan cakupan pengelolaan dan kedetailan proses-prosesnya sehingga diharapkan mempunyai pedoman yang jelas dan terintegrasi dalam penggunaan teknologi informasinya.

\subsection{Konsep Dasar Perpustakaan}

Perpustakaan adalah institusi pengelola koleksi karya tulis, karya cetak, dan/atau karya rekam secara profesional dengan sistem yang baku guna memenuhi kebutuhan pendidikan, penelitian, pelestarian, informasi, dan rekreasi para pemustaka. Koleksi perpustakaan adalah semua informasi dalam bentuk karya tulis, karya cetak, dan/atau karya rekam dalam berbagai media yang mempunyai nilai pendidikan, yang dihimpun, diolah, dan dilayankan [1]. Setiap perguruan tinggi menyelenggarakan perpustakaan yang memenuhi standar nasional perpustakaan dengan memperhatikan Standar Nasional Pendidikan. Perpustakaan perguruan tinggi mengembangkan layanan perpustakaan berbasis teknologi informasi dan komunikasi. Perpustakaan sebagai sistem pengelolaan rekaman gagasan, pemikiran, pengalaman, dan pengetahuan umat manusia, mempunyai fungsi utama melestarikan hasil budaya umat manusia tersebut, khususnya yang berbentuk dokumen karya cetak dan karya rekam lainnya, serta menyampaikan gagasan, pemikiran, pengalaman, dan pengetahuan umat manusia itu kepada generasi-generasi selanjutnya. Sasaran dari pelaksanaan fungsi ini adalah terbentuknya masyarakat yang mempunyai budaya membaca dan belajar sepanjang hayat. Di sisi lain, perpustakaan berfungsi untuk mendukung Sistem Pendidikan Nasional sebagaimana diatur dengan Undang-Undang Nomor 20 Tahun 2003 tentang Sistem Pendidikan Nasional. Perpustakaan merupakan pusat sumber informasi, ilmu pengetahuan, teknologi, kesenian, dan kebudayaan [6].

\subsection{Konsep Dasar SLiMS}

Senayan Library Management System (SLiMS) adalah perangkat lunak sistem manajemen perpustakaan (library management system) dengan sumber terbuka (Open Source Software) yang dilisensikan di bawah GPL v3. Aplikasi ini pertama kali dikembangkan dan digunakan oleh Perpustakaan Kementerian Pendidikan Nasional, Pusat Informasi dan Hubungan Masyarakat, Kementerian Pendidikan Nasional. Seiring perkembangan waktu, aplikasi ini kemudian dikembangkan oleh komunitas pengguna dan penggiat SLiMS. Aplikasi SLiMS dibangun dengan menggunakan PHP, basis data MySQL, dan pengontrol versi Git. Pada tahun 2009, SLiMS mendapat penghargaan tingkat pertama dalam ajang INAICTA 2009 untuk kategori open source [2].

Berikut ini adalah beberapa fasilitas yang tersedia untuk pengguna aplikasi Senayan Library Management
System (SLiMS) antara lain Online Public Access Catalog (OPAC) dengan thumbnail yang menampilkan cover buku; tersedia mode penelusuran yang sederhana (Simple Search) dan tingkat lanjut (Advanced Search); detail deskripsi buku juga tersedia format XML (Extensible Markup Language) untuk kebutuhan web service; manajemen data bibliografi yang efisien meminimalisasi redundansi data; manajemen masterfile/dictionary table untuk data referensial seperti GMD (General Material Designation), Tipe Koleksi, Penerbit, Pengarang, Lokasi, Kata kunci dan lain-lain; sirkulasi dengan fitur: transaksi peminjaman, pengembalian, reservasi koleksi, aturan peminjaman yang fleksibel, informasi keterlambatan dan denda; manajemen keanggotaan termasuk pembuatan kartu anggota; manajemen inventarisasi koleksi (stocktaking); laporan dan Statistik; pengelolaan terbitan berkala (Kardex); dukungan pengelolaan dokumen multimedia (.flv,.mp3) dan dokumen digital lainnya (khusus untuk pdf dalam bentuk streaming); mendukung beragam format bahasa termasuk bahasa yang tidak menggunakan penulisan selain latin; bahasa pengantar aplikasi tersedia dalam bahasa Indonesia, Inggris, Spanyol, Arab, Jerman, Thailand, Persia; dukungan Modul Union Catalog Service/Katalog Induk; counter pengunjung / absensi anggota perpustakaan; login untuk anggota dari halaman OPAC untuk melihat koleksi yang sedang dipinjam oleh anggota; modul sistem dengan fitur: Konfigurasi sistem global, Manajemen modul, Manajemen User (Staf Perpustakaan) dan grup, Pengaturan hari libur, Pembuatan barcode otomatis, dan Utilitas untuk backup; copy cataloguing dengan protocol z39.50, MARC format, dan $\mathrm{p} 2 \mathrm{p}$ service; dan pemberitahuan surat keterlambatan peminjaman melalui e-mail dengan menggunakan mail server [2].

\subsection{Penelitian Terkait}

Suatu penelitian telah dilakukan untuk melakukan penyesuaian model kualitas perangkat lunak yang sesuai dengan karakteristik aplikasi bisnis. Adapun hasil dari penelitian ini adalah bahwa perangkat lunak dalam kegiatan bisnis memiliki beberapa keunikan karakteristik. ISO 9126 yang bersifat umum dirasa tidak dapat mencakup seluruh karakteristik unik pada perangkat lunak tertentu, salah satunya aplikasi bisnis. Ditemukan karakteristik-karakteristik utama dalam suatu aplikasi bisnis yang juga melibatkan pihak pengembang, yaitu Usability, Portability, Efficiency, Reliability, Functionality, dan Traceability [7].

Penelitian lain telah dilakukan dalam membuat standar kualitas dari aplikasi permainan pada perangkat bergerak sehingga para pengembang dapat memiliki acuan untuk menilai perangkat lunak permainan yang akan dikembangkan. Adapun hasil dari penelitian ini membuktikan bahwa dengan acuan ISO 9126 maka pengembang dapat lebih memperhatikan dan mempertimbangkan faktor yang memiliki nilai 
signifikansi yang lebih besar dalam hal ini adalah aspek functionality, usability, dan portability [8].

Adapun penelitian sebelumnya telah dilakukan terkait masalah audit sistem ERP Axapta pada PT Posmi Steel Indonesia menggunakan ISO 9126 sehingga pihak perusahaan memiliki acuan dalam pengembangan sistem ERP yang ada. Hasil dari penelitian tersebut menyebutkan bahwa perlu adanya tambahan fasilitas kustomisasi pada form-form dan laporan-laporan yang terdapat dalam modul ERP Axapta sehingga mampu membuat laporan sesuai dengan jadwal yang sudah ditentukan oleh pihak manajemen [9].

Salah satu penelitian telah dilakukan untuk mengetahui tingkat kepuasan masyarakat terhadap pelayanan yang dilakukan aparatur kelurahan Bitungsari Bogor terkait pengurusan administrasi dan kegiatan lainnya. Teknik analisis data yang digunakan dalam penelitian tersebut adalah kuesioner dan metode pengolahan data menggunakan Indeks Kepuasan Masyarakat sesuai KEP/25/M.PAN/2/2004. Berdasarkan hasil pengolahan data menurut KEP/25/M.PAN/2/2004 dapat diketahui bahwa secara keseluruhan bahwa tingkat pelayanan aparatur negara di kelurahan Bitungsari berada pada tingkatan BAIK dimana kepastian biaya pelayanan dan kenyamanan lingkungan mendapatkan apresiasi SANGAT BAIK sedangkan kecepatan pelayanan mendapat sorotan yang harus lebih diperhatikan meskipun masih berada pada tingkatan BAIK [10].

\section{Metodologi Penelitian}

Penelitian dilakukan dengan menggunakan metode kuantitatif deskriptif. Pengumpulan data dan informasi sangat terkait dengan user requirement yang menggunakan aplikasi Senayan Library Management System (SLiMS) pada Perpustakaan Perguruan Tinggi. Data dan informasi diperoleh dari data primer dan data sekunder. Data primer, diperoleh dengan melakukan penyebaran kuisoner tentang aplikasi Senayan Library Management System (SLiMS) pada Perpustakaan Perguruan Tinggi Indonesia, sedangkan data sekunder diperoleh melalui studi pustaka, yaitu melalui studi literatur dan tulisan ilmiah tentang Sistem Informasi Perpustakaan dan ISO 9126.

Untuk data primer, diperoleh dari pengisian kuesioner dengan responden sebanyak 10 (sepuluh) responden yang merupakan penanggung jawab perpustakaan yang berasal dari IPMI IBS, Universitas Bakrie, Perbanas Institute Jakarta, STMIK Bina Insani, Universitas Prasetya Mulya, Universitas Agung Podomoro, Sekolah Tinggi Hukum Indonesia Jentera, Universitas Matana, STIKS Tarakanita Jakarta, dan STAI-PIQ Sumatera Barat. Responden mengisi sesuai pendapat mereka mengenai pengalaman terkait penggunaan aplikasi SLiMS pada perpustakaan perguruan tinggi masing-masing.

Dalam penelitian ini variabel yang diukur adalah hasil pengalaman pengguna SLiMS terhadap variabel pengujian kualitas aplikasi ISO 9126 dengan menggunakan aspek Functionality (Fungsionalitas), Reliability (Kehandalan), Usability (Kebergunaan), Efficiency (Efisiensi), Maintainability (Pemeliharaan), dan Portability (Portabilitas). Masing-masing aspek menggunakan skala Likert untuk mengukur sikap, pendapat, dan persepsi responden. Dengan skala Likert, variabel yang akan diukur dijabarkan menjadi indikator variabel. Kemudian indikator tersebut dijadikan sebagai titik tolak untuk menyusun item yang berupa pertanyaan atau pernyataan. Pengisian kuesioner sudah dilakukan oleh para penanggung jawab perpustakaan sekaligus pengguna langsung aplikasi SLiMS. Jawaban yang tersedia adalah sangat baik dengan nilai 4 , baik dengan nilai 3 , tidak baik dengan nilai 2 , sangat tidak baik dengan nilai 1 . Terdapat sekitar 21 butir pernyataan yang mewakili masing-masing aspek Functionality, Reliability, Usability, Efficiency, Maintainability, dan Portability.

Tabel 1. Kisi-Kisi Instrumen

\begin{tabular}{cllc}
\hline No. & \multicolumn{1}{c}{ Atribut } & Nomor Pernyataan & Jumlah \\
\hline 1. & Functionality & $1.1,1.2,1.3,1.4$ & 4 \\
2. & Reliability & $2.1,2.2,2.3$ & 3 \\
3. & Usability & $3.1,3.2,3.3,3.4$ & 4 \\
4. & Efficiency & $4.1,4.2$ & 2 \\
5. & Maintainability & $5.1,5.2,5.3,5.4$ & 4 \\
6. & Portability & 61, 6.2, 6.3,6.4 & 4 \\
\multicolumn{2}{c}{ Jumlah } \\
\hline
\end{tabular}

Setelah pengambilan data selesai maka tahap selanjutnya adalah pengolahan data dengan menghitung jumlah responden yang berpendapat sangat baik, baik, tidak baik, dan sangat tidak baik dan membuat skala Likert untuk total semua atribut dan masing-masing atribut yaitu Functionality, Reliability, Usability, Efficiency, Maintainability, dan Portability. Skala Likert dibuat dengan rumus total jawaban $\mathrm{x}$ bobot nilai x jumlah responden. Bobot nilai untuk sangat baik adalah 4 , baik adalah 3 , tidak baik adalah 2 , dan sangat tidak baik adalah 1 . Jadi, skala Likert untuk sangat baik adalah jumlah jawaban x 4 x butir soal, untuk baik adalah jumlah jawaban x $3 \times$ butir soal, untuk tidak baik adalah jumlah jawaban x $2 \times$ butir soal, dan untuk sangat tidak baik adalah jumlah jawaban x 1 x butir soal.

\section{Hasil dan Pembahasan}

4.1. Hasil Analisis Data Berdasarkan Semua Atribut dalam ISO 9126

Dasar yang digunakan untuk pengujian kualitas aplikasi SLiMS dari semua atribut secara keseluruhan adalah Skala Likert (Lihat Tabel 2. dengan perhitungan:

a. Sangat baik $=10$ responden $\times 4 \times 21$ butir soal $=$ 840

b. Baik $=10$ responden $\times 3 \times 21$ butir soal $=630$

c. Tidak baik $=10$ responden $\times 2 \times 21$ butir soal $=$ 420 
d. Sangat tidak baik $=10$ responden $\times 1 \times 21$ butir soal $=210$

Hasil pendapat responden yang diperoleh dengan cara menjumlahkan seluruh jawaban untuk seluruh atribut, diperoleh total nilai jawaban adalah 728. Dengan membandingkan hasil jawaban responden dan skala Likert, maka nilai 728 masuk kedalam klasifikasi sangat baik. Artinya bahwa aplikasi SLiMS sangat baik untuk digunakan sebagai pengelolaan perpustakaan yang ada di IPMI IBS, Universitas Bakrie, Perbanas Institute Jakarta, STMIK Bina Insani, Universitas Prasetya Mulya, Universitas Agung Podomoro, Sekolah Tinggi Hukum Indonesia Jentera, Universitas Matana, STIKS Tarakanita Jakarta, dan STAI-PIQ Sumatera Barat.

Tabel 2. Skala Likert Semua Atribut

\begin{tabular}{ccc}
\hline No. & Kategori & Skala \\
\hline 1. & Sangat Baik & $631-840$ \\
2. & Baik & $421-630$ \\
3. & Tidak Baik & $211-420$ \\
4. & Sangat Tidak Baik & $0-210$ \\
\hline
\end{tabular}

4.2. Hasil Analisis Data Berdasarkan Atribut Functionality

Dasar yang digunakan untuk pengujian kualitas aplikasi SLiMS dari atribut Functionality adalah Skala Likert Tabel 3.

Tabel 3. Skala Likert Berdasarkan Atribut Functionality

\begin{tabular}{ccc}
\hline No. & Kategori & Skala \\
\hline 1. & Sangat Baik & $121-160$ \\
2. & Baik & $81-120$ \\
3. & Tidak Baik & $41-80$ \\
4. & Sangat Tidak Baik & $0-40$ \\
\hline
\end{tabular}

Tabel 4. Hasil Pengolahan Data Atribut Functionality

\begin{tabular}{ccccccc}
\hline No. & Nama Perguruan Tinggi & 1.1 & 1.2 & 1.3 & 1.4 & Total \\
\hline 1. & IPMI IBS & 3 & 4 & 4 & 4 & 15 \\
2. & Universitas Bakrie & 4 & 4 & 4 & 4 & 16 \\
3. & Perbanas Institute Jakarta & 3 & 3 & 3 & 3 & 12 \\
4. & STMIK \& Akademi Bina & 4 & 4 & 4 & 4 & 16 \\
5. Insani & Universitas Prasetiya & 3 & 3 & 3 & 3 & 12 \\
$\quad$ Mulya & & & & & \\
6. & Universitas Agung & 4 & 4 & 4 & 4 & 16 \\
7. Podomoro & Sekolah Tinggi Hukum & 4 & 4 & 4 & 4 & 16 \\
8. Indonesia Jentera & Universitas Matana & 3 & 3 & 4 & 3 & 13 \\
9. & STIKS Tarakanita & 4 & 4 & 4 & 4 & 16 \\
10. & STAI-PIQ Sumatera Barat & 4 & 4 & 4 & 4 & 16 \\
& Jumlah & 36 & 37 & 28 & 37 & 148
\end{tabular}

Hasil pendapat responden yang diperoleh dengan cara menjumlahkan seluruh jawaban untuk atribut Functionality, diperoleh total nilai jawaban adalah 148.
Dengan membandingkan hasil jawaban responden dan skala Likert, maka nilai 148 masuk ke dalam klasifikasi sangat baik. Artinya bahwa aplikasi SLiMS menyediakan fasilitas fungsi tombol input dan edit pengguna serta tombol username dan password untuk menghindari manipulasi data dari pihak-pihak lain. Selain itu, aplikasi SLiMS mampu beriteraksi dengan aplikasi lain seperti Excel untuk mendapatkan data dari database.

\subsection{Hasil Analisis Data Berdasarkan Atribut Reliability}

Dasar yang digunakan untuk pengujian kualitas aplikasi SLiMS dari atribut Reliability adalah Skala Likert Tabel 5.

Tabel 5. Skala Likert Berdasarkan Atribut Reliability

\begin{tabular}{ccc}
\hline No. & Kategori & Skala \\
\hline 1. & Sangat Baik & $91-120$ \\
2. & Baik & $61-90$ \\
3. & Tidak Baik & $31-60$ \\
4. & Sangat Tidak Baik & $0-30$ \\
\hline
\end{tabular}

Tabel 6. Hasil Pengolahan Data Atribut Reliability

\begin{tabular}{|c|c|c|c|c|c|}
\hline No. & Nama Perguruan Tinggi & 2.1 & 2.2 & 2.3 & Total \\
\hline 1. & IPMI IBS & 4 & 1 & 2 & 7 \\
\hline 2. & Universitas Bakrie & 4 & 4 & 4 & 12 \\
\hline 3. & Perbanas Institute Jakarta & 3 & 3 & 3 & 9 \\
\hline 4. & $\begin{array}{c}\text { STMIK \& Akademi Bina } \\
\text { Insani }\end{array}$ & 4 & 4 & 4 & 12 \\
\hline 5. & Universitas Prasetiya Mulya & 3 & 3 & 3 & 9 \\
\hline 6. & Universitas Agung Podomoro & 4 & 4 & 4 & 12 \\
\hline 7. & $\begin{array}{l}\text { Sekolah Tinggi Hukum } \\
\text { Indonesia Jentera }\end{array}$ & 4 & 4 & 4 & 12 \\
\hline 8. & Universitas Matana & 3 & 3 & 2 & 8 \\
\hline 9. & STIKS Tarakanita & 4 & 4 & 4 & 12 \\
\hline \multirow[t]{2}{*}{10.} & STAI-PIQ Sumatera Barat & 4 & 4 & 4 & 12 \\
\hline & Jumlah & 37 & 34 & 34 & 105 \\
\hline
\end{tabular}

Hasil pendapat responden yang diperoleh dengan cara menjumlahkan seluruh jawaban untuk atribut Reliability, diperoleh total nilai jawaban adalah 105. Dengan membandingkan hasil jawaban responden dan skala Likert, maka nilai 105 masuk ke dalam klasifikasi sangat baik. Artinya bahwa aplikasi SLiMS mampu melakukan proses edit dalam pengolahan data perpustakaan, masih mampu beroperasi walaupun dalam keadaan offline, dan memiliki fasilitas recovery (kemampuan mengembalikan tingkat kinerja saat terjadi kegagalan sistem).

\subsection{Hasil Analisis Data Berdasarkan Atribut Usability}

Dasar yang digunakan untuk pengujian kualitas aplikasi SLiMS dari atribut Usability adalah Skala Likert Tabel 7.

Hasil pendapat responden yang diperoleh dengan cara menjumlahkan seluruh jawaban untuk atribut 
Usability, diperoleh total nilai jawaban adalah 130 . Dengan membandingkan hasil jawaban responden dan skala Likert, maka nilai 130 masuk ke dalam klasifikasi sangat baik. Artinya bahwa aplikasi SLiMS memiliki tampilan yang sangat familiar sehigga mudah untuk dioperasikan pengguna tanpa membutuhkan waktu lama dalam pembelajarannya.

Tabel 7. Skala Likert Berdasarkan Atribut Usability

\begin{tabular}{ccc}
\hline No. & Kategori & Skala \\
\hline 1. & Sangat Baik & $121-160$ \\
2. & Baik & $81-120$ \\
3. & Tidak Baik & $41-80$ \\
4. & Sangat Tidak Baik & $0-40$ \\
\hline
\end{tabular}

Tabel 8. Hasil Pengolahan Data Atribut Usability

\begin{tabular}{|c|c|c|c|c|c|c|}
\hline No. & Nama Perguruan Tinggi & 3.1 & 3.2 & 3.3 & 3.4 & Total \\
\hline 1. & IPMI IBS & 3 & 3 & 3 & 3 & 12 \\
\hline 2. & Universitas Bakrie & 4 & 4 & 4 & 4 & 16 \\
\hline 3. & Perbanas Institute Jakarta & 3 & 3 & 2 & 2 & 10 \\
\hline 4. & $\begin{array}{c}\text { STMIK \& Akademi Bina } \\
\text { Insani }\end{array}$ & 4 & 3 & 3 & 3 & 13 \\
\hline 5. & $\begin{array}{c}\text { Universitas Prasetiya } \\
\text { Mulya }\end{array}$ & 3 & 2 & 3 & 3 & 11 \\
\hline 6. & $\begin{array}{l}\text { Universitas Agung } \\
\text { Podomoro }\end{array}$ & 3 & 3 & 3 & 3 & 12 \\
\hline 7. & $\begin{array}{l}\text { Sekolah Tinggi Hukum } \\
\text { Indonesia Jentera }\end{array}$ & 4 & 4 & 4 & 4 & 16 \\
\hline 8. & Universitas Matana & 4 & 3 & 3 & 2 & 12 \\
\hline 9. & STIKS Tarakanita & 3 & 3 & 3 & 3 & 12 \\
\hline \multirow[t]{2}{*}{10.} & STAI-PIQ Sumatera Barat & 4 & 4 & 4 & 4 & 16 \\
\hline & Jumlah & 36 & 32 & 32 & 31 & 130 \\
\hline
\end{tabular}

4.5. Hasil Analisis Data Berdasarkan Atribut Efficiency

Dasar yang digunakan untuk pengujian kualitas aplikasi SLiMS dari atribut Efficiency adalah Skala Likert Tabel 9.

Tabel 9. Skala Likert Berdasarkan Atribut Efficiency

\begin{tabular}{ccc}
\hline No. & Kategori & Skala \\
\hline 1. & Sangat Baik & $61-80$ \\
2. & Baik & $41-60$ \\
3. & Tidak Baik & $21-40$ \\
4. & Sangat Tidak Baik & $0-20$ \\
\hline
\end{tabular}

Tabel 10. Hasil Pengolahan Data Atribut Efficiency

\begin{tabular}{ccccc}
\hline No. & Nama Perguruan Tinggi & 4.1 & 4.2 & Total \\
\hline 1. & IPMI IBS & 3 & 3 & 6 \\
2. & Universitas Bakrie & 4 & 3 & 7 \\
3. & Perbanas Institute Jakarta & 3 & 2 & 5 \\
4. & STMIK \& Akademi Bina Insani & 3 & 3 & 6 \\
5. & Universitas Prasetiya Mulya & 3 & 3 & 6 \\
6. & Universitas Agung Podomoro & 3 & 3 & 6 \\
7. & Sekolah Tinggi Hukum Indonesia & 4 & 4 & 8 \\
8. & Jentera & 3 & 4 & 7 \\
9. & Universitas Matana & 4 & 4 & 8 \\
\hline
\end{tabular}

\begin{tabular}{ccccc}
\hline 10. & STAI-PIQ Sumatera Barat & 4 & 4 & 8 \\
Jumlah & 34 & 33 & 67 \\
\hline
\end{tabular}

Hasil pendapat responden yang diperoleh dengan cara menjumlahkan seluruh jawaban untuk atribut Efficiency, diperoleh total nilai jawaban adalah 67 . Dengan membandingkan hasil jawaban responden dan skala Likert, maka nilai 67 masuk ke dalam klasifikasi sangat baik. Artinya bahwa aplikasi SLiMS mampu membuat penanggung jawab perpustakaan bekerja sesuai dengan waktu yang telah ditetapkan sebelumnya serta proses pencarian buku menjadi lebih cepat dari sebelumnya.

\subsection{Hasil Analisis Data Berdasarkan Atribut Maintainability}

Dasar yang digunakan untuk pengujian kualitas aplikasi SLiMS dari atribut Maintainability adalah Skala Likert Tabel 11.

Tabel 11. Skala Likert Berdasarkan Atribut Maintainability

\begin{tabular}{ccc}
\hline No. & Kategori & Skala \\
\hline 1. & Sangat Baik & $121-160$ \\
2. & Baik & $81-120$ \\
3. & Tidak Baik & $41-80$ \\
4. & Sangat Tidak Baik & $0-40$ \\
\hline
\end{tabular}

Tabel 12. Hasil Pengolahan Data Atribut Maintainability

\begin{tabular}{|c|c|c|c|c|c|c|}
\hline No. & Nama Perguruan Tinggi & 5.1 & 5.2 & 5.3 & 5.4 & Total \\
\hline 1. & IPMI IBS & 4 & 3 & 3 & 4 & 14 \\
\hline 2. & Universitas Bakrie & 4 & 4 & 4 & 4 & 16 \\
\hline 3. & Perbanas Institute Jakarta & 3 & 4 & 4 & 3 & 14 \\
\hline 4. & $\begin{array}{c}\text { STMIK \& Akademi Bina } \\
\text { Insani }\end{array}$ & 4 & 4 & 4 & 4 & 16 \\
\hline 5. & $\begin{array}{c}\text { Universitas Prasetiya } \\
\text { Mulya }\end{array}$ & 3 & 3 & 3 & 3 & 12 \\
\hline 6. & $\begin{array}{l}\text { Universitas Agung } \\
\text { Podomoro }\end{array}$ & 3 & 3 & 3 & 3 & 12 \\
\hline 7. & $\begin{array}{l}\text { Sekolah Tinggi Hukum } \\
\text { Indonesia Jentera }\end{array}$ & 4 & 4 & 4 & 4 & 16 \\
\hline 8. & Universitas Matana & 2 & 3 & 3 & 3 & 11 \\
\hline 9. & STIKS Tarakanita & 4 & 4 & 4 & 4 & 16 \\
\hline \multirow[t]{2}{*}{10.} & STAI-PIQ Sumatera Barat & 4 & 4 & 4 & 4 & 16 \\
\hline & Jumlah & 36 & 36 & 36 & 36 & 143 \\
\hline
\end{tabular}

Hasil pendapat responden yang diperoleh dengan cara menjumlahkan seluruh jawaban untuk atribut Maintainability, diperoleh total nilai jawaban adalah 143. Dengan membandingkan hasil jawaban responden dan skala Likert, maka nilai 143 masuk ke dalam klasifikasi sangat baik. Artinya bahwa aplikasi SLiMS mampu memberikan tampilan peringatan saat penanggung jawab perpustakaan salah memasukkan username dan password. Aplikasi SLiMS juga memberikan keleluasaan kepada penanggung jawab perpustakaan dalam hal penggantian password. 


\subsection{Hasil Analisis Data Berdasarkan Atribut Portability}

Dasar yang digunakan untuk pengujian kualitas aplikasi SLiMS dari atribut Portability adalah Skala Likert Tabel 13.

Tabel 13. Skala Likert Berdasarkan Atribut Portability

\begin{tabular}{ccc}
\hline No. & Kategori & Skala \\
\hline 1. & Sangat Baik & $121-160$ \\
2. & Baik & $81-120$ \\
3. & Tidak Baik & $41-80$ \\
4. & Sangat Tidak Baik & $0-40$ \\
\hline
\end{tabular}

Tabel 14. Hasil Pengolahan Data Atribut Portability

\begin{tabular}{|c|c|c|c|c|c|c|}
\hline No. & Nama Perguruan Tinggi & 6.1 & 6.2 & 6.3 & 6.4 & Total \\
\hline 1. & IPMI IBS & 3 & 3 & 4 & 3 & 13 \\
\hline 2. & Universitas Bakrie & 4 & 4 & 4 & 4 & 16 \\
\hline 3. & $\begin{array}{c}\text { Perbanas Institute } \\
\text { Jakarta }\end{array}$ & 3 & 3 & 3 & 3 & 12 \\
\hline 4. & $\begin{array}{l}\text { STMIK \& Akademi } \\
\text { Bina Insani }\end{array}$ & 4 & 4 & 3 & 4 & 15 \\
\hline 5. & $\begin{array}{c}\text { Universitas Prasetiya } \\
\text { Mulya }\end{array}$ & 3 & 3 & 3 & 3 & 12 \\
\hline 6. & $\begin{array}{l}\text { Universitas Agung } \\
\text { Podomoro }\end{array}$ & 3 & 3 & 3 & 3 & 12 \\
\hline 7. & $\begin{array}{l}\text { Sekolah Tinggi Hukum } \\
\text { Indonesia Jentera }\end{array}$ & 4 & 4 & 4 & 4 & 16 \\
\hline 8. & Universitas Matana & 2 & 2 & 3 & 3 & 10 \\
\hline 9. & STIKS Tarakanita & 4 & 3 & 3 & 3 & 13 \\
\hline 10. & $\begin{array}{c}\text { STAI-PIQ Sumatera } \\
\text { Barat }\end{array}$ & 4 & 4 & 4 & 4 & 16 \\
\hline & Jumlah & 34 & 33 & 34 & 34 & 135 \\
\hline
\end{tabular}

Hasil pendapat responden yang diperoleh dengan cara menjumlahkan seluruh jawaban untuk atribut Portability, diperoleh total nilai jawaban adalah 135 . Dengan membandingkan hasil jawaban responden dan skala Likert, maka nilai 135 masuk ke dalam klasifikasi sangat baik. Artinya bahwa aplikasi SLiMS mampu beroperasi dengan baik dalam sistem operasi Windows 7 ataupun Windows 8 core 32 bit maupun 64 bit. Aplikasi SLiMS juga mampu digunakan bersamaan dengan pernggunaan perangkat lunak lainnya, seperti Microsoft Word 2010 dan Microsoft Excel 2010. Selain itu juga, aplikasi SLiMS memberikan fasilitas menampilkan informasi kapan saatnya waktu pengembalian koleksi perpustakaan yang sedang dalam kondisi peminjaman.

\section{Kesimpulan}

Berdasarkan hasil pengujian kualitas aplikasi menggunakan ISO 9126 terhadap SLiMS bahwa SLiMS termasuk dalam kategori sangat baik. Dengan kata lain bahwa kehadiran perangkat lunak (aplikasi) perpustakaan Senayan Library Management System (SLiMS) yang handal ternyata sangat membantu para penanggung jawab perpustakaan di perguruan tinggi dalam mengelola perpustakaan, mulai dari input data, pencarian sampai dengan transaksi peminjaman dan pengembalian koleksi pustaka. Aplikasi SLiMS dapat dilihat sangat baik dalam aspek Functionality (Fungsionalitas), Reliability (Kehandalan), Usability (Kebergunaan), Efficiency (Efisiensi), Maintainability (Pemeliharaan), dan Portability (Portabilitas).Oleh karena itu aplikasi SLiMS sangat bermanfaat untuk digunakan dalam pengelolaan perpustakaan di 10 (sepuluh) perguruan tinggi tempat penelitian dilakukan, yaitu IPMI IBS, Universitas Bakrie, Perbanas Institute Jakarta, STMIK \& Akademi Bina Insani, Universitas Prasetya Mulya, Universitas Agung Podomoro, Sekolah Tinggi Hukum Indonesia Jentera, Universitas Matana, STIKS Tarakanita Jakarta, dan STAI-PIQ Sumatera Barat.

\section{Daftar Rujukan}

[1] Presiden Republik Indonesia, Undang-Undang Nomor 43 Tahun 2007 Tentang Perpustakaan. Jakarta: Sekretariat Negara Republik Indonesia, 2007.

[2] A. Nugraha and et al., "Dokumentasi SLiMS Berdasar SLiMS-7 (CENDANA) v.1," http://slims.web.id, 2009. .

[3] A. Kristanto, Perancangan Sistem Informasi dan Aplikasinya. Yogyakarta: Gava Media, 2008.

[4] R. S. Pressman, Software Engineering A Practitioner's Approach. New York: McGraw-Hill, 2010.

[5] R. Weber, Information System Control and Audit. New Jersey: Prentice Hall, 1999.

[6] Presiden Republik Indonesia, Undang-Undang Nomor 20 Tahun 2003 tentang Sistem Pendidikan Nasional. Jakarta: Sekretariat Negara Republik Indonesia, 2003.

[7] A. R. Rosyadi and S. Rochhimah, "Optimasi Proses Kerangka Kerja: Penyesuaian Model Kualitas Perangkat Lunak Pada Aplikasi Bisnis dengan Konsentrasi Pengembang," J. Buana Inform., vol. 6, no. 2, pp. 93-102, 2015.

[8] G. A. Dwi P., R. F. Insan M., and S. Rochimah, "Pengukuran Kualitas untuk Aplikasi Permainan pada Perangkat Bergerak berdasarkan ISO 9126," Ultim. InfoSys, vol. 5, no. 2, pp. 8390, 2014.

[9] H. Wicaksono, "Audit Kualitas Software ERP Axapta Menggunakan Standard ISO 9126,” Bina Insa. ICT J., vol. 3, no. 1, pp. 107-121, 2016.

[10] Pamungkas PDA, "Indeks Kepuasan Masyarakat Unit Pelayanan Kelurahan Bitungsari Bogor Menggunakan Kep/25/M.PAN/2/2004," Inf. Syst. Educ. Prof., vol. 1, no. 1, pp. 85-91, 2016 